\title{
As transições políticas no Brasil e seu efeito na educação brasileira
}

\author{
JoÃo FERREIRA DE OliveIra
}

Professor da Universidade Federal de Goiás (UFG). Doutor e pós-doutor em Educação pela Universidade de São Paulo (USP). ID ORCID: https://orcid.org/0000-0002-4135-6340

Nelson Cardoso Amaral

Professor da Universidade Federal de Goiás. Doutor em Educação pela Universidade Metodista de Piracicaba (UNIMEP). Pós-doutor em Educação pela Universidade de São Paulo (USP). ID ORCID: https://orcid.org/0000-0002-3593-9582

Resumo

O estudo analisa as transições políticas e econômicas no Brasil, principalmente as acontecidas após do impeachment da presidente Dilma Rousseff, em 2016, e dos efeitos que tiveram no campo educacional brasileiro. Por sua vez, examina as reformas políticas e as ações que consubstanciaram a transição política para o ultra neoliberalismo na condução do Estado, da economia, da política, da cultura e da educação. Essa agenda ultra neoliberal tem feito a defesa intransigente da liberdade econômica e do capitalismo financeiro-rentista, associada a uma perspectiva autoritária e conservadora, contrapor-se à construção democrático-participativa de um Estado mais social, que baliza o anseio do processo de redemocratização do país, consubstanciado em grande parte na Constituição Federal aprovada em 1988.

Palavras chave: Educação superior, Educação Pública, Neoliberalismo, Reformas neoliberais. 


\title{
La transición política en Brasil y su efecto en la educación brasileña
}

\section{Resumen}

El estudio analiza las transiciones políticas y económicas en Brasil, especialmente las que se dieron después del impeachment de la presidenta Dilma Rousseff, en 2016, y de sus efectos en el campo educativo brasileño. Examina también las reformas y las acciones que justificaron la transición política hacia el ultra-neoliberalismo en la administración del Estado, la economía, la política, la cultura y la educación. Esta agenda ultra-neoliberal ha hecho que la defensa intransigente de la libertad económica y del capitalismo financiero-rentista, asociados a una perspectiva autoritaria y conservadora, esté en oposición a la construcción democrático-participativa de un Estado más social que marca la expectativa en un proceso de redemocratización de un país que está en gran parte sustentado por la Constitución Federal de 1988.

Palabras clave: Educación universitaria; Educación pública; Neoliberalismo; Reformas neoliberales.

\section{The Political Transition in Brazil and Its Effects on Brazilian Education}

\begin{abstract}
This study analyzes the political and economic transition in Brazil, particularly after the President Dilma Rousseff's impeachment in 2016, and its effects on the Brazilian educational field. It scrutinizes some reforms, policies and actions that embody a political change to ultra-liberalism in the State, the economy, the politics, the culture, and the education. This ultra-neoliberal agenda has created the uncompromising defense of economic freedom and the financial-rentable capitalism, associated with an authoritarian and conservative perspective, in opposition to the democratic-participatory construction of a more social state, which marked out the expectations of the country's re-democratization process, substantially embodied in the Federal Constitution approved in 1988.
\end{abstract}

Keywords: Higher Education; Public Education; Neoliberalism; Neoliberal reforms. 


\section{Introdução}

O presente estudo analisa as transições políticas e econômicas no Brasil, sobretudo as acontecidas pós-impeachment da presidente Dilma Rousseff, em 2016, e dos seus efeitos no campo educacional brasileiro. Na primeira parte analisamos as mudanças políticas que contribuíram, ou não, na adoção de reformas neoliberais, até chegarmos no contexto atual, em que o Governo Federal assume uma perspectiva ultra neoliberal na economia, na forma de atuação do Estado, e no ultraconservador dos costumes sociais. Na segunda parte apresentamos as reformas, políticas e ações que consubstanciaram a transição política para o ultra neoliberalismo no Brasil, com a posse de Jair Bolsonaro na Presidência da República em janeiro de 2019. A agenda ultra neoliberal tem feito a defesa intransigente da liberdade econômica e do capitalismo financeiro-rentista, associada a uma perspectiva autoritária e conservadora, contrapor-se à construção democrático-participativa e de um Estado mais social, que baliza os anseios do processo de redemocratização do país, consubstanciado em grande parte na Constituição Federal aprovada em 1988.

\section{As transições políticas e a construção da agenda ultraliberal no Brasil}

O fim da Ditadura militar (1964-1985) no Brasil, e o consequente processo de redemocratização do país, trouxe a perspectiva da construção de um Estado democrático e mais "social", que assegurasse "os direitos sociais e individuais, a liberdade, a segurança, o bem-estar, o desenvolvimento, e a igualdade e a justiça como valores supremos de uma sociedade fraterna, pluralista e sem preconceitos", através da nova Constituição Federal de 1988 (Brasil. CF, 2020, Art. 1º). Foram definidos como direitos sociais "a educação, a saúde, a alimentação, o trabalho, a moradia, o transporte, o lazer, a segurança, a previdência social, a proteção à maternidade, à infância, e a assistência aos desamparados" (Brasil. CF, 2020, Art. 6º).

Trata-se, pois, em certa medida, de uma Constituição Federal que se estabeleceu na contramão das orientações neoliberais que vinham do Consenso de Washington, de 1980, e das políticas implementadas na Inglaterra com Margaret Thatcher (1979 a 1990), e nos EUA com Ronald Reagan (1981 a 1988). As políticas neoliberais avalizadas por organismos multilaterais, como o Banco Mundial (BM) e o Fundo Monetário Internacional (FMI), compreendidas como "políticas corretas", assentavam-se em três pilares: austeridade fiscal, privatização e liberação dos mercados no âmbito do comércio e das finanças (Stiglitz, 2002). Isso impulsionou o processo de globalização da economia me- 
diante uma ampliação do investimento externo direto (Chesnais, 1996). As orientações neoliberais incluíam ainda a desregulamentação da economia, a redução dos gastos públicos e a flexibilização do mercado de trabalho. A tese defendida na década de 1980 era que todos os países deveriam se adaptar, adotando as "políticas corretas" de inspiração neoliberal.

O neoliberalismo defendido nesse contexto constituía-se na ideologia do livre mercado, uma espécie de fundamentalismo de mercado que entendia que o sistema de concorrência, da sociedade de livre mercado, deveria ser o princípio básico de organização social (Wallerstein, 2001). Para implementar a liberdade de ação econômica, a livre iniciativa do homem econômico, no mercado autorregulável, precisava se opor a qualquer forma de economia planificada dirigida pelo Estado (Hayek, 1990). Ao Estado caberia garantir a liberdade econômica, as iniciativas econômicas individuais e a proteção da propriedade. Foi nessa direção que os organismos multilaterais atuaram fortemente a partir da década de 1980, tendo por base os interesses dos países possuidores de maior riqueza material. A internacionalização do capital produtivo, a partir do investimento externo direto das multinacionais, e do capital financeiro, que levou a uma autonomia do capital monetário perante o capital industrial, chamado por Chesnais (1996) de mundialização do capital, tornou-se o efeito mais evidente desse processo. O resultado mais perverso desse processo é a hegemonia do capital financeiro no processo de mundialização, sem regulação nacional ou global. Trata-se de dinheiro gerando dinheiro ou acumulação de capital, sem passar em grande parte pelo sistema produtor de mercadorias (Harvey, 2018).

O Brasil, sobretudo a partir da década de 1990, experimentou as contradições desse processo, sendo aos poucos dominado pelo capitalismo financeiro-rentista e sua ideologia neoliberal. A perspectiva de construir um projeto desenvolvimentista num contexto democrático e social, foi substituída pelo avanço ideológico do neoliberalismo (Bresser-Pereira, 2018). Os governos de Collor de Mello (1990-1992) e de Fernando Henrique Cardoso (1995-2002), assumiram esse ideário das virtudes do neoliberalismo e da globalização econômica num contexto de pacto liberal-dependente. O presidente Collor, em razão da acentuação da crise econômica e da corrupção, sofreu um impeachment e foi substituído por seu vice-presidente Itamar Franco (1992-1994), que retomou algumas políticas e ações de cunho menos liberais.

A posse de Luís Inácio Lula da Silva, do Partido dos Trabalhadores (PT), em 2003, representou a tentativa de retomar a construção de um projeto de nação em bases mais desenvolvimentistas ou keynesianas, a partir de um pacto nacional-popular, e mantendo, entretanto, compromissos que garantiam a reprodução do capital financeiro-rentista. Buscou-se retomar as bases de um Estado com um papel ativo, planejado, investido, de modo a favorecer o processo de industrialização, o aumento do gasto público, a distribuição de renda e, consequentemente, a redução da desigualdade social. As políticas adotadas, numa espécie de "novo Estado desenvolvimentista", foram capazes de incrementar o gasto público, estimular a produção industrial, aumentar a distribuição de renda por meio do aumento real do salário mínimo, implantar diversas políticas sociais, estimular o aumento do consumo das famílias, estimular as exportações, aumentar a oferta de emprego 
com carteira assinada e, finalmente, de ampliar o crescimento econômico do país.

As políticas de crescimento e inclusão social pelo consumo, e a ampliação significativa das políticas sociais e de ações de inclusão no contexto de um projeto neo desenvolvimentista, foram capazes de promover o crescimento do Produto Interno Bruto (РIB) e eleger Dilma Rousseff, que assumiu o cargo em 2011, também do PT, por dois mandados, dando continuidade, em certa medida, às políticas do Governo Lula da Silva (20032010). Todavia, a crise financeira internacional, a crise econômica, e a piora dos indicadores econômicos no Brasil, com a diminuição do PIB, o aumento da taxa de desemprego, a hegemonia do capital financeiro-rentista, dentre outros fatores, contribuíram para que os movimentos da sociedade política e da sociedade civil, de matriz conservadora, iniciados ainda em 2013, pudessem realizar mobilizações e manifestações da direita neoliberal e conservadora nas ruas, secundado pela grande mídia, intensificando a polarização social, e sendo o que levaria Dilma Rousseff a ser afastada e sofrer do impeachment, pelo que seria substituída por Michel Temer, do Movimento Democrático Brasileiro (MDB), a partir do 12 de maio de 2016.

Para Saviani (APUD Hermida; Lira, 2018, p.782) "a aprovação do impedimento da presidenta reeleita, sem que ficasse caracterizado o crime de responsabilidade, único motivo previsto na Constituição para justificar o impeachment, caracterizou-se como um golpe jurídico-midiático-parlamentar". Saviani afirma ainda que "rompeu-se a institucionalidade democrática, abrindo margem para todo o tipo de arbítrio". Entende ainda que "estamos vivendo um verdadeiro suicídio democrático, ou seja, as próprias instituições ditas democráticas golpeiam o Estado Democrático de Direito pela ação articulada da grande mídia, do Parlamento e do Judiciário, que, pelo golpe, se apossaram do Executivo".

Para entender esse processo do golpe, materializado no impeachment de Dilma Rousseff, é preciso retomar também o ano de 2015, quando o MDB apresentou o documento A travessia social: uma ponte para o futuro, em que defendia a adoção de políticas de ajuste fiscal, redução dos gastos públicos, cortes orçamentários, privatizações e ampliação das parcerias público-privadas, de modo a incrementar a participação da iniciativa privada, a flexibilizar o mercado de trabalho, e a ampliar a concorrência internacional. Um ponto central também seria a "regeneração do Estado", ou seja, a adoção de um Estado mínimo, enxuto e supostamente mais eficiente. Essa agenda estava em sintonia com a agenda empresarial, que também advogava aumentar a competitividade e o lucro por meio da diminuição da arrecadação do Estado, da Reforma Trabalhista, da Reforma da Previdência, da adoção de orçamento flexível do Estado mediante redução de vinculações constitucionais, e da implementação do amplo 
programa de privatizações e parcerias público-privadas.

Em 2018 ocorreram as eleições presidenciais e, dentre as várias forças liberais, neoliberais e conservadoras, elegeu-se, numa polarização com a esquerda representada por Fernando Haddad (PT), e a direita por Jair Bolsonaro, capitão reformado do exército e deputado federal por sete mandados, entre 1991 e 2018, que à época integrava o Partido Social Liberal (PSL). Sua eleição contou com forte apoio de segmentos da mídia, de empresários, do agronegócio, teve parte significativa das forças armadas, das polícias militares dos estados, da classe média e, sobretudo, da liderança das igrejas evangélicas neopentecostais. Sem participar de debates nas eleições, e sem apresentar um programa de governo mais detalhado, Jair Bolsonaro assumiu o governo em 2019 com o lema "Brasil acima de todos e Deus acima de tudo", prometendo desconstruir o Estado, privatizar tudo, combater a corrupção, acabar com os comunistas, defender a família tradicional, etc. (Nunes, 2019; Pochmann, 2019).

Desde 2016, com Michel Temer na presidência, vem ocorrendo no país reformas e propostas de emendas à Constituição Federal de 1988 que evidenciam a dimensão ultra neoliberal do grupo que assumiu o governo em âmbito federal a partir do governo de Jair Bolsonaro em 2019. Trata-se de uma agenda ultra neoliberal articulada com a extrema direita, pois além da defesa da liberdade econômica, baseada no fundamentalismo de mercado e no capitalismo financeiro-rentista, assume uma perspectiva antidemocrática, autoritária e conservadora, que emprega a própria lei contra a democracia-participativa, a atuação do Estado, a proteção, os direitos sociais; e contra os direitos dos trabalhadores num espírito de guerra implacável para minar as resistências coletivas às substâncias democráticas do Estado de direito, e da democratização do fundo público (Dardot; Laval, 2019). O autoritarismo associa-se ao darwinismo social, ou seja, a lei do mais forte, entendida como lógica natural em defesa do livre mercado concorrencial.

No campo da educação, em geral, além da busca de controle ideológico na Educação Básica e Superior, da privatização das escolas e instituições, e da defesa da educação domiciliar ${ }^{1}$,

16 Universidades $\mid$ núm. 85, julio-septiembre 2020 $\mid$ UDUAL $\mid$ DOI:https://doi.org/10.36888/udual.universidades.2020.85.274 João Ferreira de Oliveira y Nelson Cardoso Amaral $\mid$ As transições políticas no Brasil e seu efeito na educação brasileira 
ministro da Educação, num exemplo de meia verdade, afirmou no mês de abril de 2019 que "a gente gasta como os ricos e tem resultado dos pobres” (O globo, 2019), numa alusão ao fato de que o Brasil aplica o equivalente a $6,2 \%$ do PIB em educação, enquanto a Coréia do Sul, por exemplo, aplica o equivalente a $5,3 \%$, mas quando se examina o resultado do Programa Internacional de Avaliação de Estudantes (PISA), o Brasil atingiu, em média, 400 pontos, enquanto a Coréia do Sul atingiu 520 pontos (Brasil. INEP, 2020).

A meia verdade presente na afirmação do ministro está no fato que, se olharmos o tamanho do PIB do Brasil e da Coréia do Sul, e suas populações em idade educacional, de 0 a 24 anos, podemos concluir

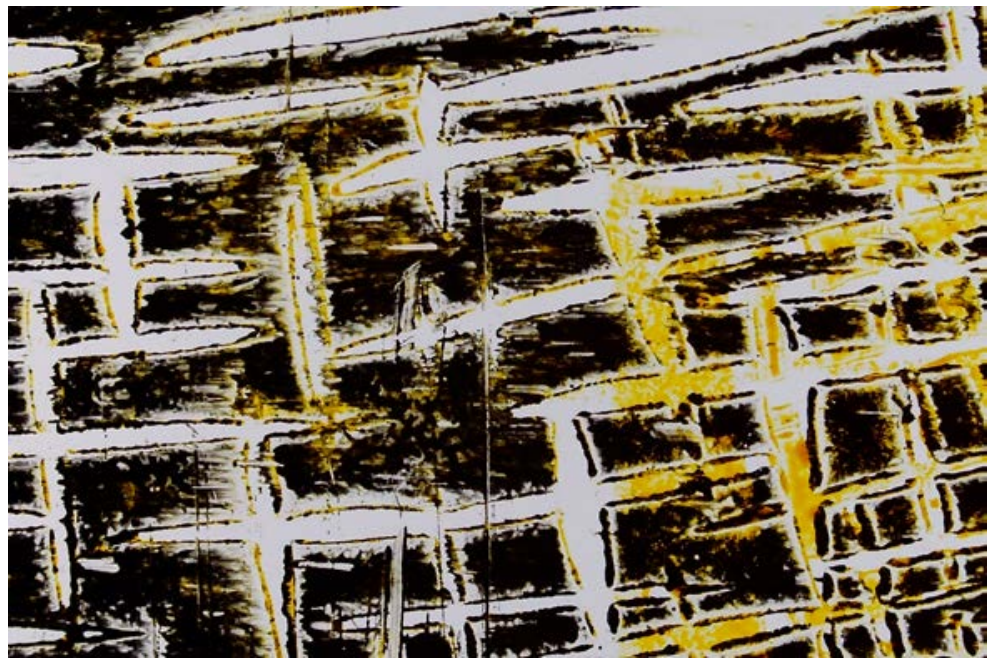
que o Brasil aplica US\$/PPP 2.558,95 em educação por pessoa em idade educacional, enquanto a Coréia do Sul aplica US\$/PPP 8.687,82.

Essas informações podem ser examinadas na tabela 01 , que mostra o valor aplicado por pessoa em idade educacional (0 a 24) nos países membros da OCDE e no Brasil. 
Tabela 01 - Valor aplicado por estudante matriculado, valores em US\$/PPP (Os valores US\$/ PPP são aqueles valores em dólares que sofreram correções para obter a paridade do poder de compra - Purchasing Power Parity - PPP)

\begin{tabular}{|c|c|c|c|c|c|}
\hline País & $\begin{array}{l}\text { PIB em } \\
\text { US\$/PPP } \\
\text { bihões }\end{array}$ & $\begin{array}{c}\text { \% PIB } \\
\text { Educação }\end{array}$ & $\begin{array}{l}\text { Valor Aplicado } \\
\text { em Educação } \\
\text { (US\$/PPp bilhões) }\end{array}$ & $\begin{array}{l}\text { População } \\
\text { em idade } \\
\text { Educacional } \\
\text { (0 a } 24 \text { anos) }\end{array}$ & $\begin{array}{l}\text { Valor aplicado em } \\
\text { Educação, por pessoa } \\
\text { em idade educacional } \\
\text { (US\$/PPP) }\end{array}$ \\
\hline Colômbia & 711,60 & 4,5 & 32,02 & 19.462 .139 & 1.645 \\
\hline México & $2.463,00$ & 4,9 & 120,69 & 55.293 .583 & 2.183 \\
\hline Brasil & $3.248,00$ & 6,2 & 201,38 & 78.694 .827 & 2.559 \\
\hline Turquia & $2.186,00$ & 4,3 & 94,00 & 32.052 .444 & 2.933 \\
\hline Chile & 452,10 & 5,4 & 24,41 & 6.116 .211 & 3.992 \\
\hline Israel & 317,10 & 5,8 & 18,39 & 3.681 .004 & 4.996 \\
\hline Rep. Eslováquia & 179,70 & 3,9 & 7,01 & 1.370 .488 & 5.114 \\
\hline Polônia & $1.126,00$ & 4,6 & 51,80 & 9.428 .937 & 5.493 \\
\hline Lituânia & 91,47 & 4,2 & 3,84 & 696.250 & 5.518 \\
\hline Hungria & 289,60 & 4,7 & 13,61 & 2.440 .025 & 5.578 \\
\hline Espanha & $1.778,00$ & 4,2 & 74,68 & 12.463 .935 & 5.991 \\
\hline Portugal & 314,10 & 4,9 & 15,39 & 2.526 .216 & 6.092 \\
\hline Itália & $2.317,00$ & 3,8 & 88,05 & 14.390 .053 & 6.119 \\
\hline Letônia & 54,02 & 5,3 & 2,86 & 457.516 & 6.258 \\
\hline Eslovênia & 71,23 & 4,8 & 3,42 & 501.489 & 6.818 \\
\hline Japão & $5.443,00$ & 3,5 & 190,51 & 27.561 .441 & 6.912 \\
\hline Estônia & 41,65 & 5,2 & 2,17 & 308.139 & 7.029 \\
\hline França & $2.856,00$ & 5,4 & 154,22 & 20.517 .282 & 7.517 \\
\hline Nova Zelândia & 189,00 & 6,4 & 12,10 & 1.603 .243 & 7.545 \\
\hline Irlanda & 353,30 & 3,7 & 13,07 & 1.720 .174 & 7.599 \\
\hline Rep. Tcheca & 375,90 & 5,6 & 21,05 & 2.608 .199 & 8.071 \\
\hline Austrália & $1.248,00$ & 5,3 & 66,14 & 8.049 .948 & 8.217 \\
\hline Reino Unido & $2.925,00$ & 5,5 & 160,88 & 19.149 .637 & 8.401 \\
\hline Coréia do Sul & $2.035,00$ & 5,3 & 107,86 & 12.414 .509 & 8.688 \\
\hline Canadá & $1.774,00$ & 5,3 & 94,02 & 10.226 .405 & 9.194 \\
\hline Estados Unidos & $19.490,00$ & 5,0 & 974,50 & 104.348 .886 & 9.339 \\
\hline Bélgica & 529,20 & 6,5 & 34,40 & 3.331 .027 & 10.327 \\
\hline Holanda & 924,40 & 5,5 & 50,84 & 4.841 .967 & 10.500 \\
\hline Alemanha & $4.199,00$ & 4,8 & 201,55 & 18.196 .243 & 11.077 \\
\hline Finlândia & 244,90 & 6,9 & 16,90 & 1.524 .408 & 11.085 \\
\hline Áustria & 441,00 & 5,5 & 24,26 & 2.159 .048 & 11.234 \\
\hline Islândia & 18,18 & 7,5 & 1,36 & 116.303 & 11.724 \\
\hline Suíça & 523,10 & 5,1 & 26,68 & 2.162 .348 & 12.338 \\
\hline Dinamarca & 287,80 & 7,6 & 21,87 & 1.687 .455 & 12.962 \\
\hline Luxemburgo & 62,11 & 3,9 & 2,42 & 179.151 & 13.521 \\
\hline Suécia & 518,00 & 7,7 & 39,89 & 2.908 .730 & 13.713 \\
\hline Noruega & 381,20 & 8,0 & 30,50 & 1.639 .138 & 18.605 \\
\hline
\end{tabular}

Fonte: The World Factbook (EUA.CIA, 2020) 
Numa outra oportunidade, o próprio presidente Jair Bolsonaro, num exemplo de afirmação totalmente falsa, assegurou no dia 8 de abril de 2019 que: "Poucas universidades têm pesquisa e, dessas poucas, a grande parte está na iniciativa privada" (Jovem Pan, 2019).

É de reconhecimento mundial que, no Brasil, as universidades públicas lideram a produção do conhecimento, ciência, tecnologia e inovação. Para se confirmar o grau de comprovação deste fato, basta verificar que o quantitativo de programas de pós-graduação, mestrado e/ou doutorado, nas instituições públicas brasileiras (federais, estaduais e municipais) atinge $81,4 \%$ dos programas, locais em que são realizadas a maior parte das pesquisas no Brasil.

Esse perfil determinado historicamente, pode ser visualizado examinando a tabela 02 , que mostra o quantitativo dos programas de pós-graduação stricto sensu existentes em cada um dos estados e no DF, nos âmbitos federal, estadual, municipal e privado. No âmbito federal, estão separados os programas existentes nas Universidades Federais daqueles das outras instituições federais que ofertam a pós-graduação stricto sensu (Institutos Federais de Educação, Ciência e Tecnologia, Centros Federais de Educação Tecnológica, Escola Nacional de Ciências Estatísticas, Instituto Militar de Engenharia e Instituto Tecnológico da Aeronáutica). O exame desta tabela, por si só, já bastaria para podermos afirmar que a análise presidencial é absolutamente uma absurda inverdade.

Verifica-se, portanto, que é o conjunto de Universidades Federais, instaladas em todos os Estados brasileiros e DF, que promove em seus 2.180 programas de pós-graduação stricto sensu a pesquisa e a extensão que procuram diminuir as assimetrias regionais e a desigualdade brasileira. As universidades públicas, sobretudo pela via dos programas de pós-graduação, respondem pelo $95 \%$ da produção científica brasileira (Clarivate Analytics, 2019). 
Tabela 02 - Quantitativo de programas de pós-graduação stricto sensu (MS ou DR) em cada um dos Estados e no DF, nos âmbitos federal, estadual, municipal e privado - 2016

\begin{tabular}{|c|c|c|c|c|c|c|c|}
\hline Estado & $\begin{array}{c}\text { Univ. } \\
\text { Federais (a) }\end{array}$ & $\begin{array}{l}\text { Outras } \\
\text { IES } \\
\text { Federais }\end{array}$ & Estaduais & Municipais & Privadas & $\begin{array}{l}\text { Total } \\
\text { (b) }\end{array}$ & $\begin{array}{c}\% \\
(a / b)\end{array}$ \\
\hline Rondônia & 12 & - & - & - & - & 12 & 100 \\
\hline Acre & 10 & - & - & - & - & 10 & 100 \\
\hline Amazonas & 36 & 11 & 9 & - & 2 & 58 & 62 \\
\hline Roraima & 10 & - & 4 & - & - & 14 & 71 \\
\hline Pará & 85 & 5 & 9 & - & 8 & 107 & 79 \\
\hline Amapá & 4 & - & - & - & - & 4 & 100 \\
\hline Tocantins & 22 & - & - & - & - & 22 & 100 \\
\hline Maranhão & 29 & 2 & 11 & - & 4 & 46 & 63 \\
\hline Piauí & 36 & 1 & 2 & - & 1 & 40 & 90 \\
\hline Ceará & 69 & 6 & 32 & - & 15 & 122 & 57 \\
\hline Rio Gr. do Norte & 81 & 2 & 14 & - & 7 & 104 & 78 \\
\hline Paraíba & 87 & 1 & 16 & - & 2 & 106 & 82 \\
\hline Pernambuco & 123 & 4 & 15 & - & 19 & 161 & 76 \\
\hline Alagoas & 35 & - & 1 & - & 3 & 39 & 90 \\
\hline Sergipe & 44 & 1 & - & - & 5 & 50 & 88 \\
\hline Bahia & 91 & 4 & 66 & - & 17 & 178 & 51 \\
\hline Minas Gerais & 320 & 27 & 16 & - & 60 & 423 & 76 \\
\hline Espírito Santo & 55 & 6 & - & - & 13 & 74 & 74 \\
\hline Rio de Janeiro & 242 & 79 & 73 & - & 85 & 479 & 51 \\
\hline São Paulo & 131 & 17 & 492 & 16 & 243 & 899 & 15 \\
\hline Paraná & 124 & 1 & 149 & - & 52 & 326 & 38 \\
\hline Santa Catarina & 79 & 2 & 30 & 15 & 41 & 167 & 47 \\
\hline Rio Gr. do Sul & 207 & 32 & - & - & 155 & 394 & 53 \\
\hline Mato G. do Sul & 51 & - & 10 & - & 7 & 68 & 75 \\
\hline Mato Grosso & 38 & 1 & 11 & - & 7 & 57 & 67 \\
\hline Goiás & 66 & 11 & 10 & 1 & 14 & 102 & 65 \\
\hline Distrito Federal & 93 & 4 & 1 & - & 15 & 113 & 82 \\
\hline Total Geral & 2.180 & 217 & 971 & 32 & 775 & 4.175 & 52 \\
\hline
\end{tabular}

Fonte: (Brasil. CAPES, 2019) 
A dimensão ultraliberal do grupo que assumiu o Governo Federal está presente, inequivocamente, na Proposta de Emenda à Constituição no 188 (PEC-188) encaminhada ao Senado Federal, realizada em novembro de 2019, em que elimina os planos plurianuais, desvincula ao máximo possível os recursos associados às políticas sociais, e transfere para os estados, DF e municípios, as responsabilidades para que haja a diminuição das desigualdades sociais.

Além disto, ao gerir os recursos dos fundos públicos, arrecadados da população brasileira, transfere recursos públicos para o setor privado realizar ações sociais e proteger, com todas as liberações possíveis, as despesas financeiras associadas ao capital financeiro.

Algumas ações previstas nessa PEC-188 ilustram as dimensões ultraliberais do grupo que assumiu o Governo Federal:

a) No Brasil há uma vinculação constitucional de recursos do fundo público que devem ser aplicados em educação e saúde, sendo uma vinculação para cada um desses setores sociais. A proposta governamental é a de que haja uma vinculação acoplada, de tal modo que um setor ao aplicar mais recursos que o mínimo estabelecido, implicaria que o outro setor pudesse aplicar menos recursos financeiros que o mínimo estabelecido. Dessa forma, seria instalada uma perversa disputa de recursos financeiros entre esses dois setores, que, exatamente, precisam de mais recursos para superar as dificuldades existentes e diminuir as desigualdades brasileiras nesses setores.

b) O Governo Federal brasileiro aloca recursos financeiros para o desenvolvimento de ações relacionadas à educação básica nos estados, DF e municípios, para a aquisição de material didático, transporte escolar, alimentação, assistência à saúde, etc. A PEC-188 estabelece que, a partir de sua aprovação, não passariam a existir mais o aporte de recursos extras do âmbito federal para essas atividades, que passariam a ser suportadas apenas por recursos associados aos outros entes federados.

c) O texto constitucional estabelece que os recursos públicos podem se destinar ao pagamento de bolsas de estudo nos locais de residência dos estudantes em que há falta de vagas na rede pública, mas o ente federado ficaria com a obrigação de expandir a sua rede. A PEC-188 propõe uma alteração que desobriga o ente federado desta expansão, podendo, então, pagar bolsas de estudo para toda a educação básica em escolas cadastradas -que podem ser escolas privadas-, podendo se configurar como uma situação perene naquela localidade.

d) Ainda no Governo Temer (2016-2018) foi aprovada uma emenda à Constituição Federal, a de $\mathrm{n}^{0} 95$, que congelou os recursos para o pagamento de pessoal, água, luz, telefone, limpeza, vigilância, material de consumo, construções, aquisição de equipamentos, etc., por 20 anos, até o ano de 2036. Desta forma, essas despesas do Poder Executivo somente poderiam ser reajustadas pela inflação do ano anterior. A PEC-188 estabelece a possibilidade da redução dos salários dos servidores públicos e condicionalidades ainda mais restritivas que o congelamento, na possibilidade da existência de crises, já existentes, na economia brasileira. 
e) A vinculação de parte dos recursos associados à exploração do petróleo brasileiro, existente na camada pré-sal da costa do país, para a educação e saúde estabelecida em lei, seria revogada caso a PEC-188 fosse aprovada.

f) Não seria mais preciso elaborar Planos Plurianuais que especificavam "de forma regionalizada" as diretrizes, objetivos e metas da administração pública federal para as despesas de capital, outras delas decorrentes, e para as relativas aos programas de duração continuada"; revoga-se também o parágrafo que explicitava que os orçamentos compatibilizados com os planos teriam as funções "de reduzir as desigualdades inter-regionais" (Brasil. CF, 2020, Art. $\left.165, \S 1^{\circ}\right)$.

Desta forma, explicita-se a oposição a qualquer forma de economia planificada, e, ao Estado, caberia garantir a liberdade econômica e a diminuição, na visão ultra neoliberal, da atuação do Estado.

No curto espaço de tempo que vai de 2016 a 2019, já se percebe claramente a materialização das políticas implementadas pelos governos de Michael Temer e Jair Bolsonaro, que seguem as diretrizes apresentadas anteriormente. Na Educação Básica (0 a 17 anos), a análise de algumas ações do Governo Federal em relação a estados, DF e municípios, já mostram, claramente, a retirada da Educação Básica do contexto do Governo Federal.

A ação da União e Concessão de Bolsas de apoio à Educação Básica, tem o objetivo de conceder:

bolsas para formação profissional, qualificação e atualização de professores participantes de projetos de formação, estudos, pesquisa e desenvolvimento de metodologias de ensino, assim como para estudantes de licenciatura, incentivando a formação inicial e continuada de professores para a Educação Básica, inclusive do Sistema Universidade Aberta do Brasil, e o intercâmbio entre instituições formadoras de Educação Superior por meio de parcerias e acordos, visando à melhoria da qualidade do ensino; concessão de bolsas de iniciação júnior, objetivando atrair alunos de ensino médio para a carreira docente (Brasil. MTO, 2014).

A figura 01 mostra a evolução dos recursos financeiros aplicados nesta ação no periodo 2010-2019:

Figura 01. Ação: Concessão de Bolsas de Apoio i Educação Básica

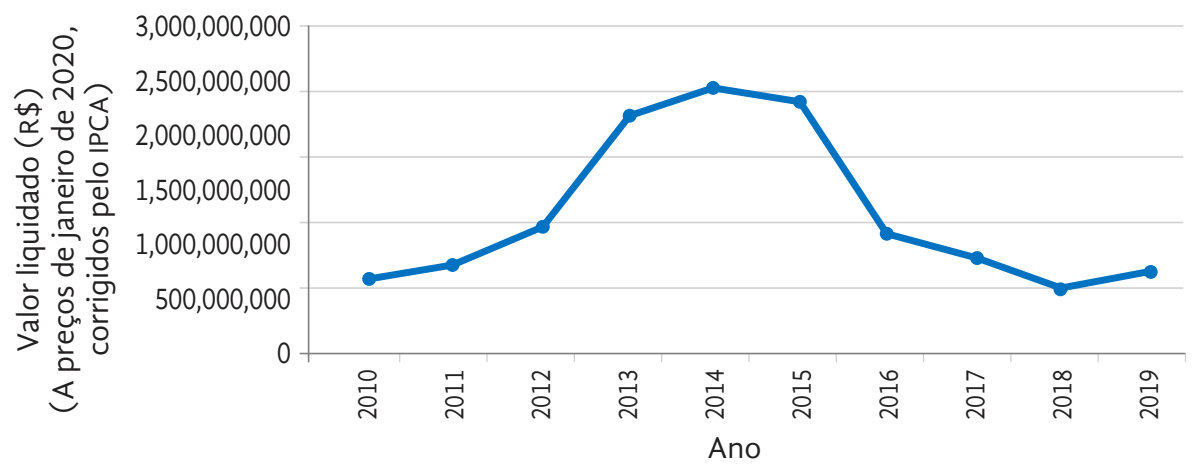

Fonte: Execução Orçamentária de União (Brasil. Camara, 2020). 
Nota-se uma abrupta queda em 2016, saindo de valores próximos a R\$ 2,5 bilhões para valores próximos de R\$ 750 milhões em 2019.

A ação Dinheiro Direto nas escolas para a Educação Básica se refere à prestação de:

assistência financeira, em caráter suplementar, às escolas públicas da Educação Básica das redes estaduais, municipais e do Distrito Federal, às escolas privadas da educação especial, às escolas de educação especial qualificadas como beneficentes de assistência social ou de atendimento direto e gratuito ao público, às escolas mantidas por entidades de tais gêneros, e aos polos presenciais do sistema da Universidade Aberta do Brasil - UAB que ofertem programas de formação inicial ou continuada a profissionais da Educação Básica, com o objetivo de aprimorar a infraestrutura física e pedagógica, e reforçar a autogestão educacional (Brasil. MTO, 2014).

A figura 02 apresenta a evolução dos recursos financeiros associados a esta ação no periodo 2010-2019:

Figura 02. Ação: Dinheiro Direto na Escola para a Educação Básica

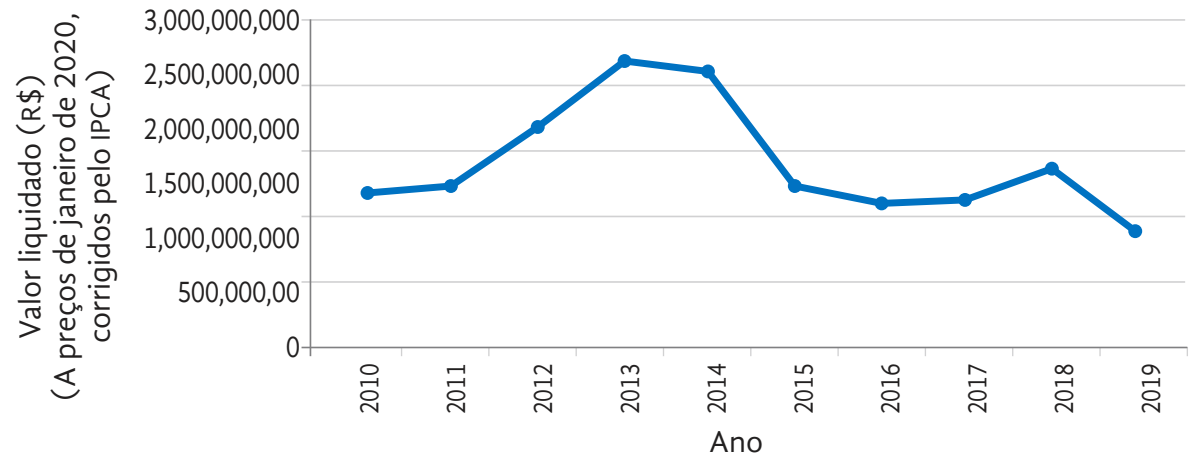

Fonte: Execução Orçamentária de União (Brasil. Camara, 2020).

Houve uma redução de valores um pouco acima de R 2,5 bilhões em 2014 para R\$ 1 bilhão em 2019.

A ação denominada Apoio ao Transporte Escolar na Educação Básica tem o objetivo de assegurar "recursos suplementares para oferta de transporte escolar aos alunos residentes em área rural, contribuindo para seu acesso e permanência nas redes públicas de Educação Básica” (Brasil. MTO, 2014). Essa ação teve seus recursos diminuídos de R 1 bilhão para valores inferiores a R\$ 800 milhões em 2019, chegando a ficar próximo dos R\$ 600 milhões em 2017.

A figura 03 mostra a evolução dos recursos financeiros aplicados nesta ação desde o ano de 2010 até o 2019: 
Figura 03. Ação: Apoio ao Transporte Escolar na Educação Básica

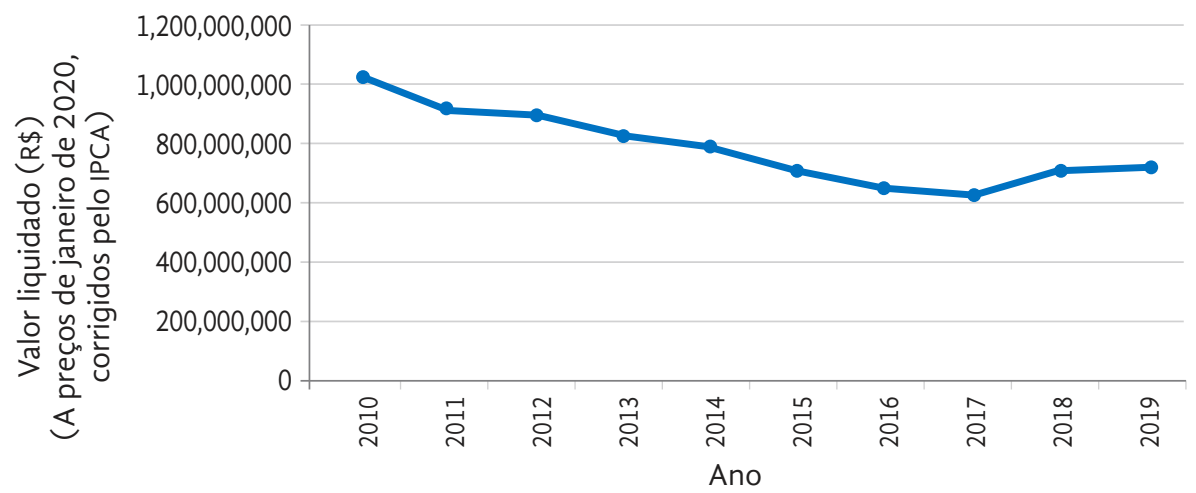

Fonte: Execução Orçamentária de União (Brasil. Camara, 2020).

A ação chamada Caminho da Escola se propõe a adquirir:

veículos padronizados para o transporte escolar, inclusive acessórios de segurança e apoio às atividades inerentes à certificação, com o objetivo de garantir qualidade e segurança do deslocamento dos estudantes matriculados na Educação Básica das redes estaduais, municipais e do DF, prioritariamente da zona rural, com o objetivo de assegurar seu acesso e permanência nas escolas, reduzir a evasão escolar, renovar a frota de veículos escolares das redes públicas de Educação Básica, e reduzir seu preço de aquisição (Brasil. MTO, 2014).

A figura 04 mostra a evolução dos recursos financeiros vinculados a esta ação:

Figura 04. Ação: Camino da Escola

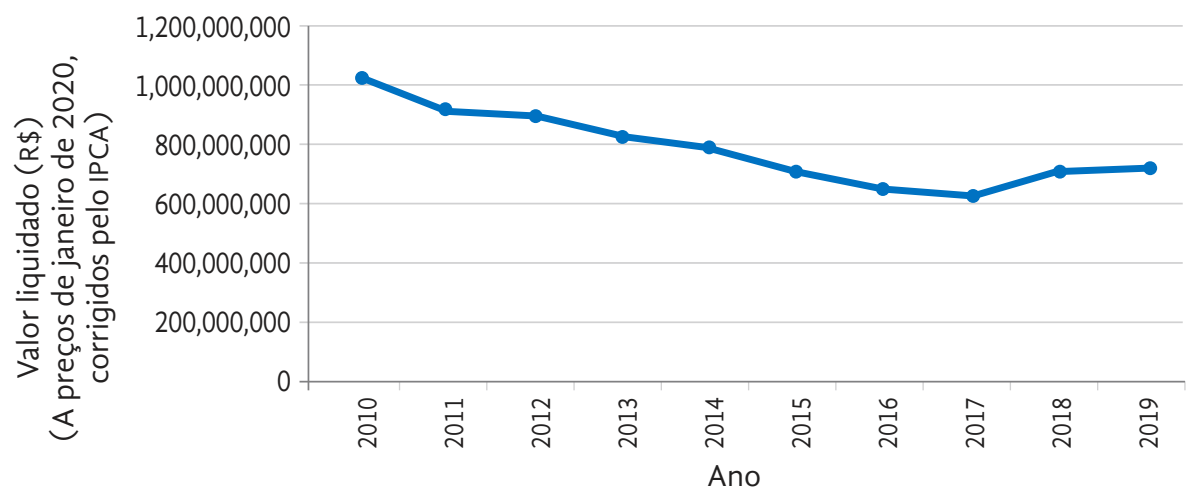

Fonte: Execução Orçamentária de União (Brasil. Camara, 2020). 
Esta ação atingiu valores superiores a R\$ 1 bilhão em 2012 e, praticamente, atingiu valores nulos de 2017 a 2019.

A ação Tecnologia da Informação e Comunicação para a Educação Básica propôs dar apoio:

Técnico, pedagógico, material e financeiro para a infraestrutura tecnológica de conexão, transmissão e recepção de dados, imagens, vídeos, e sons, por meio da internet, televisão e outras mídias ativas, por satélite, soluções terrestres, ou novas tecnologias de conexão que venham a ser desenvolvidas para utilização pedagógica no processo de ensino-aprendizagem na educação básica. (...) A produção e aquisição de equipamentos específicos para ampliar a oferta do atendimento educacional especializado, para promoção e garantia da acessibilidade e especificidades das populações do campo, quilombolas, indígenas, pessoas com deficiência, e a educação de jovens e adultos, permite, desta forma, a melhoria no processo de ensino-aprendizagem e da inclusão na Educação Básica, por intermédio do uso pedagógico das TIC nos processos educacionais (Brasil. MTO, 2014).

Esta ação foi implementada e atingiu um máximo de R\$ 600 milhões em 2010, se reduzindo a valores insignificantes a partir de 2014, como é mostrado na figura 05:

\section{Figura 05. Ação Tecnologia da Informação e Comunicação para a Educação Básica}

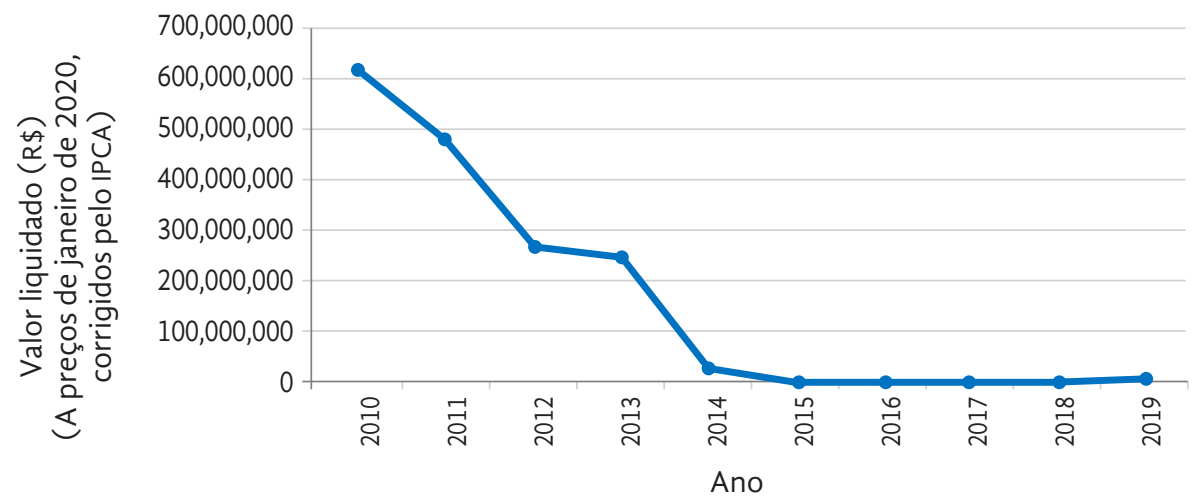

Fonte: Execução Orçamentária de União (Brasil. Camara, 2020).

Uma das ações mais importantes no contexto brasileiro é a que se propõe a Produção, Aquisição e Distribuição de Livros e Materiais Didáticos e Pedagógicos para a Educação Básica, que tem como objetivo a:

produção, aquisição e distribuição de livros, acervos bibliográficos, materiais didáticos, pedagógicos e de referência, e materiais complementares que possam ser disponibilizados para os alunos, professores e unidades educacionais, 
considerando as especificidades da população indígena, do campo e da quilombola; o ensino da história e cultura indígena, afro-brasileira, e africana; o atendimento educacional especializado, a educação de jovens e adultos; a educação em direitos humanos; a sustentabilidade socioambiental; as relações étnico raciais, de gênero, diversidade sexual; e os direitos da criança e do adolescente, com o objetivo de auxiliar o desenvolvimento da prática pedagógica e de estimular a leitura e a escrita na Educação Básica (Brasil. MTO, 2014).

A evolução dos recursos está mostrada na figura 06:

Figura 06. Ação: Produção, Aquisição e Distribuição de Livros e Materiais Didáticos e Pedagógicos para a Educação Básica

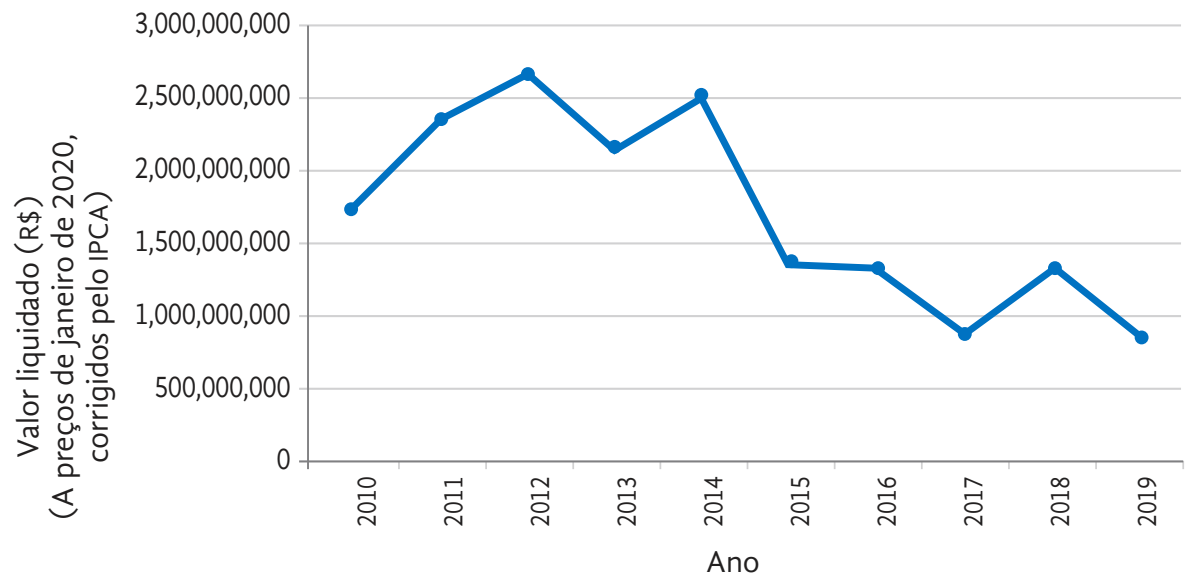

Fonte: Execução Orçamentária de União (Brasil. Camara, 2020).

A evolução dos recursos explicita claramente uma queda vertiginosa dos recursos financeiros a partir de 2014 , saindo de $\mathrm{R} \$ 2,5$ bilhões e chegando a valores da ordem de R\$ 900 em 2019.

Pode-se notar, por esses poucos exemplos, e considerando a importância dos objetivos estabelecidos em cada um deles, que a retirada dos recursos financeiros pertencentes à União, significará um grande retrocesso para a Educação Básica brasileira nos anos futuros. É preciso notar que essas políticas já foram implementadas antes mesmo da aprovação da PEC188 , o que agudiza as previsões que podem ser feitas sobre o grau das reduções financeiras nas ações a serem implementadas após a aprovação desta emenda constitucional.

Na Educação Superior, em especial no âmbito das Universidades Federais, houve diminuição nos recursos para outras despesas correntes (pagamento de água, luz, energia elétrica, telefonia, limpeza, vigilância, material de consumo, etc.), para investimentos (construções, equipamentos, etc.), e, além disto, no contexto da ciência e tecnologia, houve grande redução nos recursos financeiros associados à Coordenação de Aperfeiçoamento de Pessoal de Nível Superior (CAPES) e ao Conselho Nacional de Desenvolvimento Tecnológico e Científico (CNPq). 
A evolução dos recursos financeiros das Universidades Federais para outras despesas correntes (ODC) e para investimentos (INV), pode ser examinada nas figuras 07 e 08 :

Figura 07. UFS: Outras despesas correntes

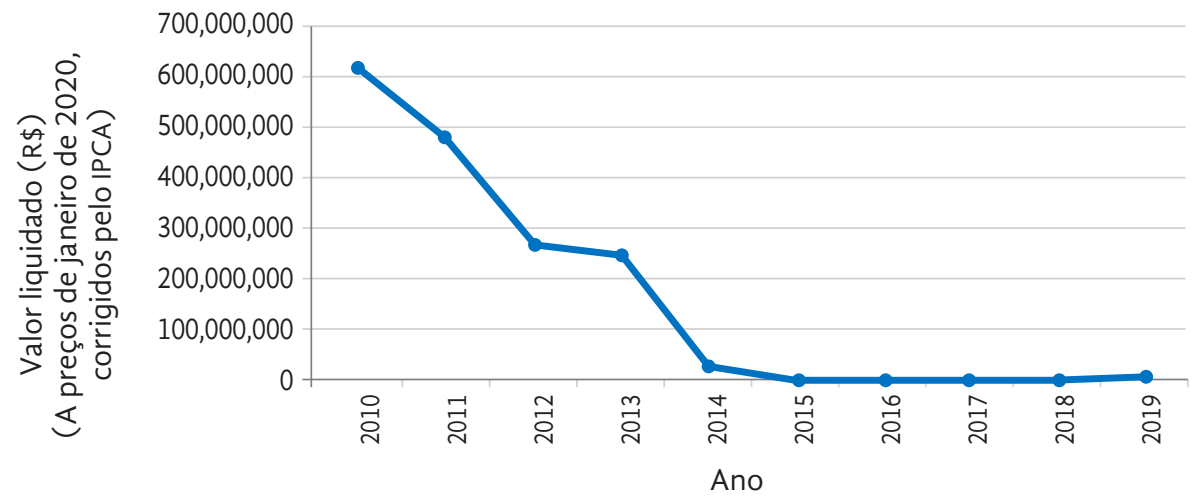

Fonte: Execução Orçamentária de União (Brasil. Camara, 2020).

Figura 08. UFs: Investimentos

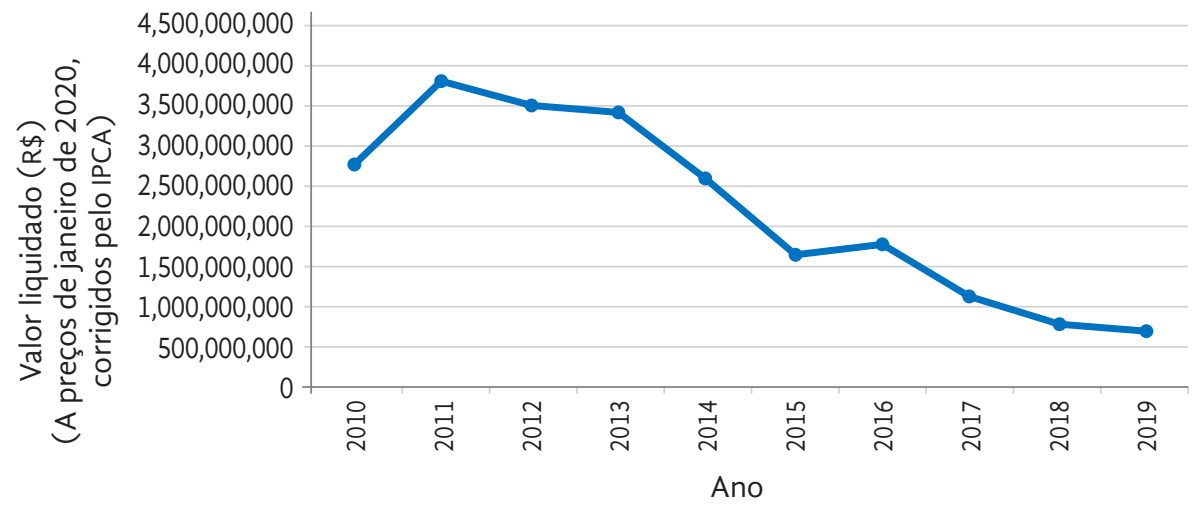

Fonte: Execução Orçamentária de União (Brasil. Camara, 2020).

Note-se que as ODC caíram mais de R\$ 1 bilhão a partir de 2013, e os investimentos sofreram uma drástica redução a partir desse ano, passando de quase R\$3,5 bilhões a um valor em torno de R\$ 750 milhões em 2019.

Esta involução de recursos, que vai ser continuada nos próximos anos, poderá resultar em perdas irreparáveis para esse conjunto de instituições que foram construídas nas últimas sete décadas, e que possuem grande prestígio perante a população brasileira e a comunidade acadêmica internacional.

O Brasil possui instalado um robusto sistema de ciência e tecnologia que dá suporte à pós-graduação stricto sensu, e à pesquisa nas instituições 
de Educação Superior brasileiras, e esse sistema também está em risco. As figuras 09 e 10 mostram a evolução dos recursos financeiros associados ao CNPq e à CAPES no periodo 2010-2019:

Figura 09. Evolução dos recursos do CNPq

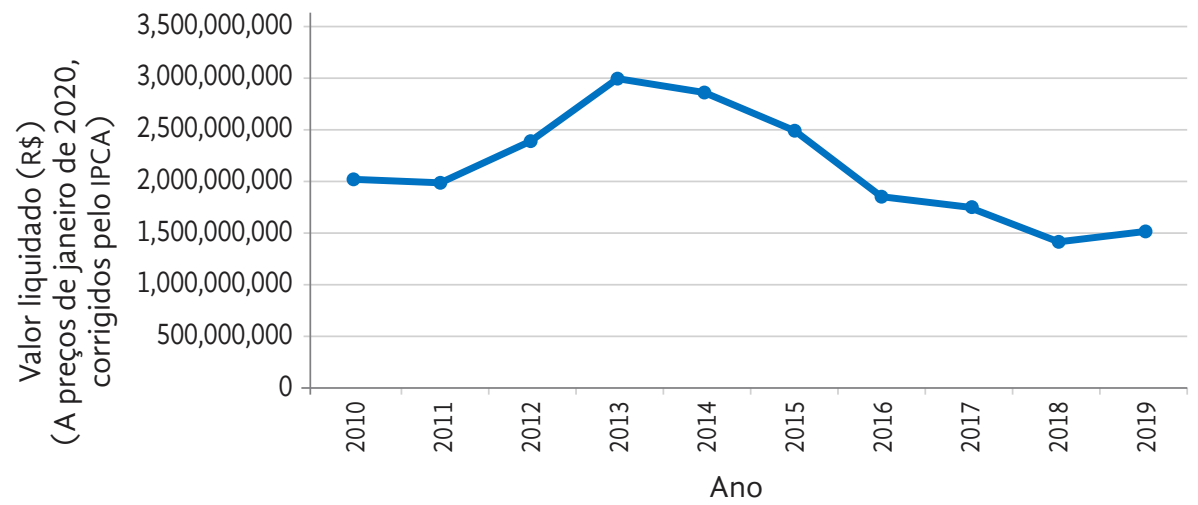

Fonte: Execução Orçamentária de União (Brasil. Camara, 2020).

Figura 10. Evolução dos recursos da CAPES

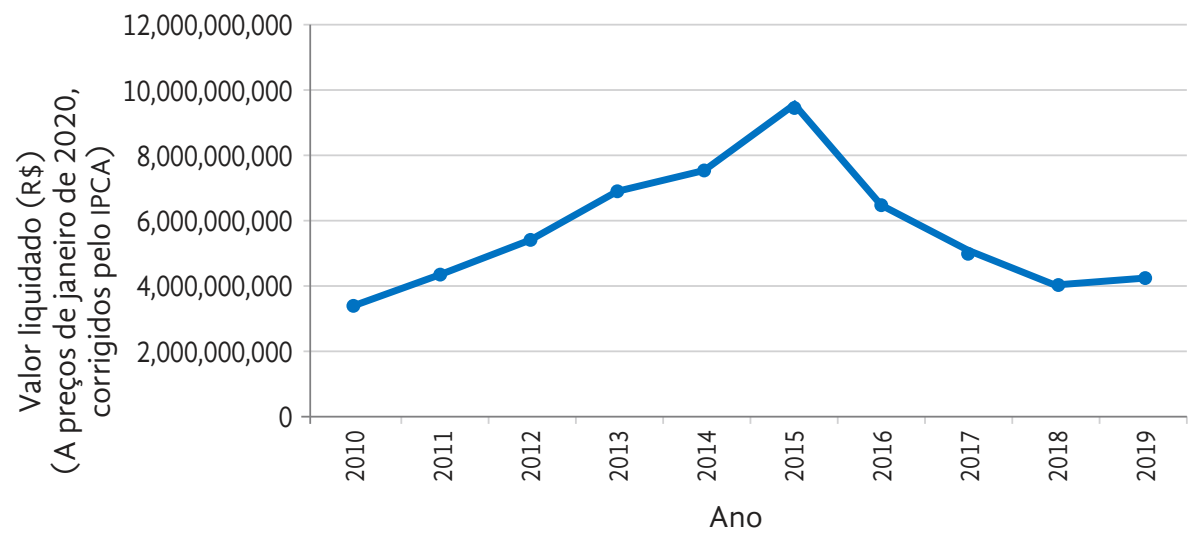

Fonte: Execução Orçamentária de União (Brasil. Camara, 2020).

Nesse periodo, os recursos do CNPq saíram do patamar de R 3,5 bilhões a R $\$ 1,5$ bilhões, enquanto o da Capes, de valores próximos a $\mathrm{R} \$ 10$ bilhões em 2015, atingiu valores em torno de R\$ 4 bilhões em 2019. São, portanto, reduções drásticas que, se não foram revertidas, podem instalar um colapso nos programas de pós-graduação stricto sensu, e nas pesquisas desenvolvidas nas instituições de Educação Superior no Brasil, que são realizadas, sobretudo, nas instituições públicas.

Nessa mesma lógica, a avaliação da Educação Superior também é modificada e pautada por mecanismos mais amplos de flexibilização e (des) regulamentação, rumo a uma perspectiva de autorregulação das IES privadas. O Estado vem diminuindo seu papel regulador e supervisor do sis- 


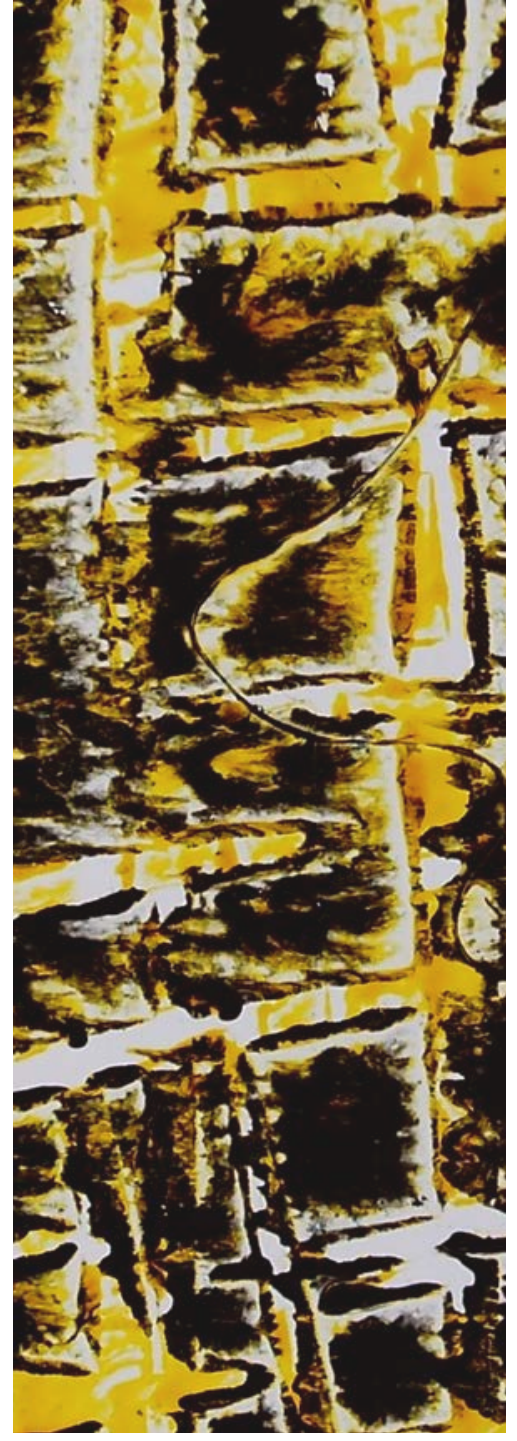

tema de Educação Superior por meio da adoção de critérios mais flexíveis e facilitadores da expansão de cursos e vagas. Mudanças substantivas têm sido implementadas no Sistema Nacional de Avaliação da Educação Superior (SINAES), e nos processos de regulação e supervisão desse nível de educação, como se observa na flexibilização de normas na graduação e na pós-graduação, com adoção de critérios mais subjetivos, e a consequente eliminação de critérios mais objetivos. De modo geral, as mudanças na base legal da Educação Superior evidenciam: a simplificação de processos, a diminuição de exigências, a concessão de mais autonomia para aspectos específicos, a simplificação dos processos e das atribuições de órgãos, etc. Essas mudanças estão em sintonia, pois, com a orientação neoliberal que vem sendo institucionalizada na condução da economia, do Estado, e da regulação da vida social. A orientação básica é que o próprio mercado deve regular o setor de Educação Superior, ou seja, são os empresários, ou os agentes econômicos, interessados em investir e realizar a autovalorização do capital, os que devem guiar a oferta dos serviços de Educação Superior.

\section{Considerações finais}

As reformas e políticas ultra neoliberais propostas e/ou implementadas no Brasil vem, como foi mostrado anteriormente, (des) construindo rapidamente um Estado de pendor mais social, sobretudo aquele erigido na Constituição Federal de 1988. O discurso ultra neoliberal se apresenta como o retorno à ordem econômica "natural", proclamando o "fim das ideologias". As orientações econômicas, da crença ou da ideologia neoliberal, associadas a uma ideologia conservadora, parecem ter enorme força simbólica na sociedade brasileira, sobretudo porque conta com amplo apoio do empresariado, dos defensores do capital financeiro-rentista, da grande mídia, e das forças armadas, de parte importante do judiciário e de grupos evangélicos neopentecostais, correlação de forças que se estruturou mais a partir da eleição de Jair Bolsonaro. Sua força simbólica também conta com as orientações dos organismos econômicos multilaterais, que proclamam a globalização, a flexibilização, a desregulamentação, a privatização, etc., ou seja, o caminho único do fundamentalismo de mercado. 
O Estado brasileiro, por meio da institucionalização das orientações ultra neoliberais, foi sendo moldado para atender os interesses dos grupos empresariais, do capital financeiro-rentista, e dos segmentos conservadores e autoritários da sociedade. A eliminação dos direitos sociais e da proteção e remuneração do trabalho, mediante a limitação de gastos primários, sobretudo sociais, da Reforma Trabalhista, da Reforma da Previdência, da Reforma da Liberdade Econômica (instituída pela Lei $n^{\circ}$ 13.874, de 20 set. 2019), dentre outras, já produz efeitos em termos da precarização do trabalho, piora dos serviços públicos, da diminuição das políticas sociais, e da ampliação da desigualdade social no país. As reformas, políticas e ações em curso, tem levado o Estado a se ajustar a uma "nova" orientação econômica, em contraposição a uma perspectiva de projeto nacional mais afinado ao desenvolvimento econômico e social, e com a geração de bens coletivos que busque reduzir a enorme desigualdade social no país.

Além da defesa do mercado livre e da institucionalização do ultra neoliberalismo, mesmo nos ministérios voltados para as áreas mais sociais (como os de Previdência, Saúde, Educação, Trabalho, Moradia, etc.), tem se fortalecido, por meio da ação do Estado, o poder nas mãos da direita conservadora, interessada em estabelecer uma "nova" ordem nos valores, costumes e comportamentos sociais. Mudanças têm sido efetuadas para implementar uma crença comum, ou melhor, um sentimento de que são precisos mais remédios da ortodoxia da economia neoliberal para se chegar no crescimento econômico, com menos espaços da democracia-participativa, com menos formação e crítica nas universidades, na impressa livre e crítico-investigativa, e nos movimentos sociais, com o fortalecimento do Estado penal que, via de regra, pune ou mata os mais pobres, os negros, os precarizados do mundo do trabalho e os que estão sendo eliminados pela via do desemprego estrutural.

As mudanças constitucionais, as reformas econômicas e políticas de inspiração ultra neoliberal, e as intervenções e cortes nos orçamentos do Governo Federal no Brasil, inclusive no campo da educação, evidenciam a opção pelo favorecimento do capital, sobretudo financeiro-rentista, em detrimento da remuneração da força de trabalho (mesmo que atua de forma indireta mediante políticas sociais que ampliam o direito à educação, saúde, alimentação, trabalho, moradia, transporte, lazer, segurança, previdência social, proteção à maternidade e à infância, e assistência aos desamparados). A retoma da construção de um Estado de pendor social, na direção da democratização do fundo público e a redução da desigualdade social, continua a ser um grande desafio no Brasil, dado, sobretudo, às transições, forças e tramas político-econômicas de nossa história recente e conjuntura atual. 


\section{Referências}

Bourdieu, Pierre. (1998). Contrafogos: táticas para enfrentar a invasão neoliberal. Rio de Janeiro: Jorge Zahar Ed.

Brasil. CF. Constituição Federal de 1988. Constituição da República Federativa do Brasil. Disponível em: http://www.planalto.gov.br/ccivil_03/constituicao/constituicao.htm. Acesso em: 01 de abr. 2020.

Brasil. Camara. LOA 2010-2019, Consultas e Relatórios de Execução: Banco de Dados Acess p/ download (Execução Orçamentária da União). Disponível em: < www2.camara.leg.br/orçamento-da-uniao/leis-orcamentarias/loa>. Acesso em: 02 de abr. de 2020.

Brasil. CAPES. Sistema de Informações Georreferenciadas - GEOCAPES. Disponível em: https:// geocapes.gov.br/geocapes/ (acesso em 15 de mai. de 2019).

Brasil. INEP. PISA 2018 results. Disponível em:<oecd.org/pisa/publications/pisa-2018-results. htm>. Acesso em 15 de abr. de 2020.

Brasil. MTO. Ações Orçamentárias Integrantes da Lei Orçamentária para 2014. Disponível em: $<\mathrm{http}$ ://www.orcamentofederal.gov.br/orcamentos-anuais/orcamento-2014/arquivos-cadastros-de-acoes/2101.pdf $>$. Acesso em 10 de abr. de 2020.

Bresser-Pereira, Luiz Carlos. (2018). Em busca do desenvolvimento perdido: um projeto novo-desenvolvimentista para o Brasil. Rio de Janeiro: FGV Editora.

Chesnais, François. (1996). A mundialização do capital. São Paulo: Xamã.

Dardot, Pierre Dardot; LAVAL, Christian. Anatomia do novo neoliberalismo. Revista IHU on-lin. Disponível em: http://www.ihu.unisinos.br/78-noticias/591075-anatomia-do-novo-neoliberalismo-artigo-de-pierre-dardot-e-christian-laval. Acesso em: 25 Julho 2019.

EUA.CIA. The World Factbook. Disponível em:<cia.org/library/publications/the-world-factbook/>. Acesso em 05 de abr. 2020.

Freitas, Luiz Carlos. (2018). A reforma empresarial da educação: nova direita, velhas ideias. São Paulo: Expressão Popular.

Harvey, David. (2018). A loucura da razão econômica: Marx e o capital no século XXI. São Paulo: Boitempo.

Hayek, Friedrich August von. (1990). O caminho da servidão. Rio de Janeiro: Instituto Liberal.

Hermida, Jorge F.; LIRA, Jailton de S. (2018). Políticas educacionais em tempos de golpe: entrevista com Dermeval Saviani. Educ. Soc., Campinas, v. 39, nº. 144, p.779-794, jul.-set.

Jovem pan. Entrevista do Presidente da República à Jovem Pan, no día 08/04/2019. Disponível em: www.unicamp.br/unicamp/ju/artigos/luiz-marques/ciencia-versus-bolsonaro (acesso em 20 de set. de 2019).

Metropoles. Temos que desconstruir muita coisa, diz Bolsonaro sobre o Brasil, 18/03/2019. Disponível em:<metropolis.com/mundo/politica-int/temos-que-desconstruir-muita-coisa-diz-bolsonaro-sobre-Brasil).>. Acesso em: 14 de abr. de 2020.

O globo. A gente gasta como os ricos e tem resultado dos pobres. Disponível em: www.g1.globo. com/educacao/noticia/2019/04/08/a-gente-gasta-como-os-ricos-e-tem-resultado-dos-pobres-leia-frases-do-novo-ministro-da-educacao.ghtml (acesso em 20 de jun. de 2019).

Stiglitz, Joseph E. (2002). A globalização e seus malefícios. São Paulo: Futura.

Wallerstein, Immanuel. (2001). Capitalismo histórico \& Civilização capitalista. Rio de Janeiro: contraponto. 